\title{
IMMIGRANT FAMILY IN DISTRESS: ASSISTING IMMIGRANT PARENTS OF JUVENILE DELINQUENTS
}

\section{Liat Yakhnich and Meir Teichman}

\begin{abstract}
This exploratory and descriptive paper depicts a unique pilot program in Israel aimed at assisting and supporting immigrant families from the Former Soviet Union (FSU) whose children have been involved in criminal behavior after the immigration. The program is a joint venture of the Immigrant Parents Forum association, the Welfare Services Department at the Ministry of Immigrant Absorption (MIA), and the Juvenile Probation Service (JPS) at the Ministry of Welfare and Social Services. It provides structured help to the families of these youngsters, including mediation with the JPS and other officials and public bodies in the community, parental training, guidance, and emotional support. The program description, including case illustrations, is based on the program's internal documents and interviews with the following key figures: the chairwoman of the Immigrant Parents Forum, two program coordinators, the program supervisor, the director of the JPS, the deputy head of the regional JPS office in charge of implementing the program on a trial basis, and the regional social worker at the Ministry of Immigrant Absorption. Although the program is implemented in a particular social and political context, it may offer ideas about assisting immigrant parents regardless of origin, ethnicity, and specific social circumstances.
\end{abstract}

Keywords: immigrant adolescents, immigrant parents, youth delinquency, probation service

Liat Yakhnich, Ph.D., (the corresponding author) Youth Development Department, Beit Berl Academic College, Beit Berl 49905, Israel. E-mail: liatyakhnich@yahoo.com

Meir Teichman, Ph.D., Professor Emeritus, Tel-Aviv University School of Social Work, Tel-Aviv 69978, Israel. E-mail: teichma@post.tau.ac.il 
The children of immigrant parents account for approximately $10 \%$ of all children in Israel (Cosher, Ben-Arie, \& Cohen, 2011); 53\% of these are from the former Soviet Union (FSU): in other words, 5.3\% of all children. Studies of this population reveal high levels of risk-taking and anti-social behavior that is manifested in high dropout rates from school, delinquency, substance abuse, etc. (Cosher et al., 2011; Edelstein \& Bar-Hamburger, 2007; Horowitz \& Brosh, 2011; Mirsky, 2012). These findings are consistent with those of other studies around the world, which point to high levels of risk-taking and anti-social behavior among adolescent immigrants by comparison with their parents or their non-immigrant peers (Bankston, 1998; Janssen et al., 2004; Killian, 2002; van Leeuwen, Rodgers, Bui, Pirlot, \& Chabrol, 2014 ). However, a few authors suggest immigrant adolescents' adaptation may be as good as, and sometimes even better than, that of their peers. This phenomenon has been referred to as the "immigrant paradox" (Sam, Vedder, Liebkind, Neto, \& Virta, 2008).

\section{Immigrant youth and anti-social behavior}

Immigration can pose enormous challenges to an adolescent's psychological and social functioning. Differences in language, values, norms, and rules of social interaction can hamper his or her development. The immigration experience is especially complex for adolescents, since their mental equilibrium is more delicate than that of adults and they require a more stable environment to develop normally (Mann, 2004; Mirsky \& Peretz, 2006). In addition, immigration can undermine an adolescent's process of identity formation (Mann, 2004; Mirsky \& Peretz, 2006; Tsang, Irving, Alaggia, Chau, \& Benjamin, 2003).

One of the adverse consequences observed in this context is the high incidence of antisocial behavior among immigrant youth. The literature explains this phenomenon as follows: the criminological view sees variables such as conflicting values, exposure to discrimination, social marginalization, and lack of social control as significant factors (Killian, 2002); while the psychological approach attributes it to the sense of loss and grief experienced by the immigrant youth (Henry, Stiles, \& Biran, 2005); to developmental challenges and the immaturity of adolescence (Mirsky \& Peretz, 2006); and to the cultural characteristics of immigrant youths (Tartakovsky \& Mirsky 2001).

According to Titzmann, Raabe, and Silbereisen's (2008) model of delinquent behavior among immigrant youth, there are three major factors that can either foster or inhibit the emergence of anti-social behavior: peer influence, school involvement, and family relationships. An immigrant youth subjected to negative peer influences has fewer normative social networks to counter the negative impact. His or her parents have fewer means and ability to be involved in their child's life, they may lack the social support network needed to deal with his behavioral problems, and they are often too preoccupied with their own adaptation problems to provide effective parental oversight. Similarly, the immigrant youth who is exposed to risk factors within the family will have fewer external resources to counter the negative impact at home. The support that he might receive in school may be hampered by language difficulties, lack of positive feedback from teachers, and classmates' rejection - all of which may disrupt the process of internalizing pro-social norms of the sort usually acquired at school. In these circumstances, the immigration experience can become a kind of transition period in which previous behavioral patterns are disrupted, requiring the youth's entire developmental system to be reconfigured (Granic \& Patterson, 2006). As a result, the positive effect of the social environment, which would normally curb the negative effects through oversight or support, is undermined, and risk factors associated with criminal behavior come to the fore (Titzmann et al., 2008). 
One of the factors extensively studied in relation to the adaptation of immigrant adolescents is their cultural and national identity (Phinney, Horenczyk, Liebkind, \& Vedder, 2001; Walsh \& Tartakovsky, 2011). The findings are consistent with the main claims of Berry's acculturation theory (Berry, 1997), which posits four possible strategies of cultural adaptation (acculturation) among immigrants. The strategy that has been found to be the most likely to promote the immigrant's normal psychological adjustment is integration, meaning identification with both the culture of origin and the host culture (Berry, 1997; van Leeuwen et al., 2014). Adolescents' positive relationship with both identities (identity of origin and identity of the host society) is essential to a normal process of adaptation (Walsh \& Tarta-kovsky, 2011). Conversely, the marginalization strategy - a sense of not belonging to any culture - is thought to be a risk factor for anti-social behavior among immigrant youths. Adolescents with a marginal identity are in a state of diminished social supervision (Edelstein \& BarHamburger, 2007). Many of them feel alienated toward both the host society and the culture of origin, and anti-social behavior offers them a means of expressing anger and anomie, a sense of belonging, a social status, and an alternative culture. Parents' attitude can do much to contribute to the youths' positive connection with their cultural identity (Phinney et al., 2001). The parents' openness to the host culture, while maintaining a positive (and coercion-free) connection with the culture of origin, correlates to well-being among young immigrants (Henry, Stiles, Biran, \& Hinkle, 2008).

In this context, it would be important to mention the phenomenon of "third culture kids" (TCK) who develop a unique cultural identity that synthesizes aspects of their home and host cultures, but differs from both (Hoersting \& Jenkins, 2011). These children often form a cross-cultural identity and feel a sense of belonging to a TCK cultural group rather than to home or host cultures (Pollock \& Van Reken, 1999). The phenomenon sometimes is named "cultural homelessness" (Hoersting \& Jenkins, 2011). Similar to youth whose acculturation strategy is marginalization (Berry, 1997), these youngsters live in a framework that may include experiences that do not belong to any specific cultural reference group (Vivero \& Jenkins, 1999). There are both positive and negative aspects of this uniqueness. The positive experiences associated with "cultural homelessness" are being multilingual and demonstrating cross-cultural competence. The negative aspects are a sense of not belonging to any group, and feelings of loneliness and disorientation (Hoersting \& Jenkins, 2011).

\section{The family context of anti-social behavior among immigrant adolescents}

Anti-social behavior among adolescents is strongly linked to familial factors. According to the theory of social control, family cohesion, a strong positive relationship between the youth and parents, and parental monitoring significantly reduce youth engagement in negative behavior (Hirschi, 1969; Ward \& Laughlin, 2003). Conversely, a negative relationship with parents increases the risk of the youth's engaging in negative behavior.

Studies conducted in Israel have found that the family of origin plays a key role in explaining delinquency among immigrant adolescents. A study by Horowitz \& Brosh (2011) found that a significant percentage of immigrant youths have difficult family environments. Non-normative behaviors in the youth were related to multiple conflicts, financial hardship, and a harsh perception of immigration experience and of family life. A study by Edelstein \& Bar-Hamburger (2007) found a significant negative association of family cohesion and parental monitoring with psychoactive substance use and delinquent behavior among immigrant adolescents. Their conclusion was that adolescent immigrants at risk often feel anger toward 
their parents and the host society, and that anti-social behavior offers them a means of displacing this anger (Edelstein \& Bar-Hamburger, 2007).

Immigrant families with adolescent children must contend with two formidable situations at once: a youth in the throes of socialization and identity formation, and parents struggling to redefine their own identity within the new country. These challenges are compounded when the immigrant parents are also emotionally inaccessible to their adolescent children and unable to provide for their developmental needs, including supervision and containing their negative impulses (Mann, 2004).

The fact that children acquire the language and an understanding of the local culture faster than their parents significantly affects the family relationships, deepens the social and linguistic divide between them and, in many instances, results in role reversal within the family (Oznobishin \& Kurman, 2009; Trickett \& Jones, 2007). This gulf puts the adolescent in a position of authority within the family. In Oznobishin and Kurman's (2009) study, immigrant subjects reported having a more dominant position in their relationship with their parents, and less family support, compared to their non-immigrant peers. They also characterized the experience of acting as their parents' translators in negative terms, citing embarrassment, psychological burden, and perception of their parents as dependent and weak. This combination of linguistic mediation on the parents' behalf, and the low levels of family support, was found to be linked to the low self-esteem possessed by immigrant children (Oznobishin \& Kurman, 2009), and to their higher emotional distress (Jones, Trickett, \& Birman, 2012).

Portes and Rumbaut (2001) argue that the social adjustment of children of immigrants depends on the following factors: the social context (attitudes of the society and support by the local immigrant community); the personal resources (educational level, professional skills, etc.) of the children's parents; and family factors such as extended family availability and the presence of significant adult figures. Adjustment problems (e.g., anti-social behavior) are more typical among children who encounter hostility and a lack of support during their absorption, and come from broken and dysfunctional families, whose parents have low human capital. These children may experience a dissonant acculturation, characterized by rejecting their families' language and values. In families where parents have failed to learn the new local language, this situation may result in the loss of their parental authority and an inability to influence their children (Portes, Fernandez-Kelly, \& Haller, 2009).

\section{FSU immigrant families}

Immigrant families from the European parts of the Former Soviet Union are typically small, consisting of one or two children. The parents are highly motivated to invest in the children's upbringing, especially their education (Yakhnich, 2010). These families often delay the onset of the child's independence (see Leipzig, 2006; Mirsky, 1997), and relations between parents and children are often characterized by a high degree of protectiveness and involvement (occasionally over-involvement), coupled with a demand for obedience and selfdiscipline (Slonim-Nevo, Sharaga, \& Mirsky, 1999). These cultural attributes may heighten the distress felt by immigrant youths when exposed to the local culture, which is typically much less authoritarian and encourages them to rebel against their parents and the values they represent. Indeed, in their study of FSU immigrant adolescents, Dwairy and Dor (2009) underline that the discrepancy between their parents' parenting style and the permissive nature of Israeli society creates difficulties for these children. 
Another factor that may make parenting more difficult in immigrant families is changes in the parents' image of the "adaptive adult" - that is, the concept reflecting parents' ideal image of how their children should be as adults (Roer-Strier \& Rosenthal, 2001). This image guides parental child-rearing practices, and is shaped by their own cultural background. In the case of FSU immigrants, the image of the "adaptive adult" is typically one of self-discipline, conformity, strong work ethic, and academic excellence (Yakhnich, in press). The parent is perceived as having an authoritative and didactic role, setting clear norms of behavior and responsible for their implementation through enforcement, encouragement, and personal example. When a family arrives in a new society, the parents may preserve certain parts of the "adaptive adult" image and parental roles that they brought from the country of origin, while adopting other aspects of the local culture as a result of interaction with the new society (Strier \& Roer-Strier, 2005). This can result in undesirable changes in patterns of parenting, such as an abrupt transition from an authoritarian parenting approach with strict boundaries and limited communication with the children, to a highly permissive one with no rules and an egalitarian relationship with the adolescent. Such sudden transitions may leave the child confused and directionless, undermine the parent's authority and status, derail essential parental involvement and supervision, and possibly give rise to anti-social behavior (Yakhnich, in press).

Immigrants from the FSU seem reluctant to refer to public psychosocial services (Sakin, 2009). There are fundamental differences between such services in the FSU and in western countries, including Israel, which is perhaps why many immigrants find it difficult to establish a proper relationship with them (Sakin, 2009). Those who do approach the authorities for help are deeply mistrustful of them. The therapeutic relationship with FSU immigrants typically involves fear of stigma, the sense of loss of control, difficulty in creating trust and discussing personal issues, and a high degree of ambivalence (Leipzig, 2006; Sakin, 2009). Anti-social behavior on the part of an adolescent child is often perceived as tarnishing the entire family, and therefore the tendency is to avoid discussing it with "strangers" such as professionals (Bronshtein \& Bar-On, 2008; Sakin, 2009). Accordingly, we assume that families with adolescent children who are most at risk, due to difficulties in adjusting to the new country, may avoid seeking help for themselves and for their children, or refuse to cooperate with officials who instigate the initial contact.

\section{Treatment of delinquent youth in juvenile probation}

The Juvenile Probation Service in Israel is a social-therapeutic service with powers of enforcement provided by the Ministry of Social Affairs and Social Services (2013). It handles minors at the age of criminal responsibility (12 to 18 years), who have been referred to it by police or by the court after indictment or conviction for a criminal offense and have been placed under a care order. In Israel, juvenile probation officers are social workers who specialize in care for juvenile delinquents. Their operational assumption is that juvenile delinquency is a symptom or product of difficulties and hardships experienced by minors at the personal, family, and social levels (Ministry of Social Affairs and Social Services, 2013). Accordingly, the probation officer's task is to identify, diagnose, treat and help these minors tackle these difficulties, by all appropriate means of treatment and rehabilitation, with a view to returning them to normative function. The Juvenile Probation Service (JPS) provides the following services: evaluation of the psychosocial status of youth; individual and group-based care according the type of offense committed; assistance and counseling to the youth's parents; and arranging placements outside the home. It also collaborates with community agen- 
cies to arrange personal mentoring for youths, employment training, integrating them into educational frameworks, and so forth.

\section{The experimental “Family Assistance Program”}

The experimental Family Assistance Program is the brainchild of the Forum of Immigrant Parents (FIP) - “a nonprofit organization established in 1995 by immigrant parents, educationalists and intellectuals from the FSU to support and advance immigrant families" (Forum of Immigrant Parents, 2014). Its purpose is to help the families of immigrants from the FSU whose children are in trouble with the law, in the belief that by helping and empowering the parents, they can help rehabilitate the juvenile delinquent child. The program was developed in collaboration with the Ministry of Immigrant Absorption (MIA), and the Juvenile Probation Service (JPS) at the Ministry of Social Affairs.

As mentioned previously, this paper is exploratory and descriptive, and is not based on research. Information about the program was derived from the program's internal documents (e.g., program brochure, annual reports, etc.) and interviews with the following seven key figures: the chairwoman of the Forum of Immigrant Parents, the program coordinator, two of the counselors, the director of the Juvenile Probation Service, the deputy District Officer in charge of implementing the program, and a district social worker of the Ministry of Immigrant Absorption. The interviews were conducted by one of the authors. Some officials were interviewed only once; others were interviewed several times (personally and by telephone) in order to complete the essential information.

The program’s aims are:

1. To promote collaboration between parents and probation officers and other officials involved in the adolescent's rehabilitation, and to enable parents to take advantage of the help and rehabilitation services offered by the JPS.

2. To help the family as a whole create the necessary environment for the youth to be rehabilitated by facilitating communication between parents and children.

A program coordinator (a psychiatrist and group facilitator by training) and three counselors of varied professional backgrounds but with a shared affinity for educational work run the program. It has been operating on a trial basis for some years in several communities, and after evaluation its scope is expected to widen. Since it was launched the program has helped about 600 families, in close collaboration with the JPS. Currently, the program is handling about 150 families.

The sole criterion for acceptance into the program is for the youth's family to have immigrated from the FSU after 1990. It should be noted that apart from exceptional cases, most of the adolescents whose families participate in the program immigrated to Israel at a young age (some have been born in Israel), and got involved in criminal behavior after the immigration. When such a youth is referred to the JPS in one of the towns where the program operates, he or she is automatically redirected to the program. The probation officer approaches the family for its permission and refers it to the counselor in their region, detailing the areas in which the program help is needed. The counselor then contacts the family and arranges an introductory meeting, where they map out the family's needs for intervention or help. The counselor's role covers three main areas: 
1. Mediation between the family and the JPS. Some of the youths' families refuse to cooperate with the service, due to language problems, unfamiliarity with the service, or simple suspicion and apprehension. Part of the counselor's job is to explain to the family what the JPS does, and to encourage them to cooperate, for the youth's sake. They then organize a series of joint meetings with the probation officer, in which they serve as mediator. The counselor, who speaks Russian and is familiar with the family's culture, manages to win their trust and supports their relationship with the probation officer. In addition, he helps the probation officers - who are usually not members of the "Russian" community themselves - to understand the distinctive cultural reasons behind the families' function and behavior.

2. Mediation between the family and community services, such as the National Insurance Institute, schools, police, and others. The counselor helps the family to form relationships with these officials and make use of available services that it may not know about, and refers individual family members to other professionals as required. They also help other children in the family by arranging public extra-curricular activities and courses, help with schoolwork, etc.

3. Parental guidance in areas such as interacting with the adolescent child, setting boundaries, handling conflicts, while providing parents with emotional support. Counselors also arrange informative meetings where parents can meet professionals and representatives of various public agencies, support groups and other activities, with a view to empowering the parents and supporting them. The underlying premise behind all the work in the program is that strengthening the family is a key to the adolescent's rehabilitation. It is important to note that the counselor is not engaged in therapeutic work per se though, as few are trained psychotherapists.

The relationship with the family can last between three months to three years, with the average being around one year. Once the charges against the youth are dropped, the counselor notifies the family that its participation in the program terminates. In most cases, this occurs approximately two months after the legal charges are dropped. A review of program records to date reveals that, since its onset, only one family dropped out of the program prior to the criminal charges being dropped.

\section{Case illustrations}

The following cases illustrate the typical actions and involvement of a program counselor with a family.

Case One: A Juvenile Probation officer contacted the program coordinator about a 14year-old boy who had been indicted for assault. The parents had immigrated to Israel five years before, and were living with their son in a one-room apartment, in highly crowded conditions. They were struggling financially, as both worked at menial jobs for little pay. Both had found it difficult to adapt to the country and still spoke no Hebrew. When the boy was placed under house arrest, the family's situation deteriorated even further, since one of the conditions of the order was that he be supervised and escorted outside the home by one of the parents at all times, which meant that the father had to leave his job, and the mother became the family's sole provider. The probation officer had been unable to contact the family, due to language difficulties and because parents were unwilling to meet her. However, the parents were willing to cooperate with the program counselor, to whom they confided their sense of helplessness, disorientation and misgivings about the probation service, which they suspected of colluding with the police and conspiring to take their son away. 
The counselor began by explaining the role of the probation officer to the parents, and explaining to the probation officer why the parents had been so suspicious of her. This allowed the parents and the probation officer to begin a process of positive cooperation whenever the counselor was present. As a first step toward building trust, it was decided with the probation officer, to recommend to the court that the boy be permitted to attend school once again, provided his father escorted him there and back. Once achieved, the counselor arranged for the family to be reimbursed for transportation costs to and from school - then, with the probation officer, recommended to the court that the father be released from his chaperone duties, and helped him find a new job. These positive outcomes of cooperation increased the parents' trust in both the counselor and the probation officer. Throughout this period the counselor also provided guidance to the parents, with particular emphasis on establishing constructive communication, setting boundaries, and restoring parental authority.

Over time, the parents reported a significant improvement in the relationship with their son. After seven months, the boy continued to be monitored by the Probation Service, but the house arrest order was dropped, and the counselor maintained contact with the parents. Eighteen months after the family was referred to the program, the boy's criminal record was expunged, with no negative consequences to his future prospects. In a follow-up check three years later, the boy had not been referred back to the Probation Service.

Case Two: The program counselor was approached by a probation officer about a 15year-old boy, who was involved in drug abuse. During the meetings, the counselor discovered the boy's parents each had substantially different educational approaches, which caused multiple conflicts between the two. The conflicts occurred in the boy's presence, and granted him an opportunity to manipulate his parents and get almost everything he wanted. The boy's father demonstrated a lack of involvement in his son education, expressed indifference to his situation, and attributed his problems to the "lack of discipline” in Israeli schools.

The counselor worked with both parents to establish a cohesive educational position and promote cooperation between them, and encouraged the boy's father to take responsibility and get involved in his son's life. He informed the father as to educational approaches in the school and helped him to reduce his level of helplessness and frustration. The parents also participated in parents' group and attended educational lectures held in the program. Within a year the parents reported a significant improvement in their relationships with their son.

At the same time, the counselor served as a mediator between the family and the school authorities. There was a significant deterioration in the boy's achievements, he missed school on many occasions, and his teachers expressed doubts as to his ability to advance to a higher class. The counselor met with the school counselor and recruited her support, as well as helped the family to have scholastic assistance for their son. The boy's schools achievements improved significantly, which contributed greatly to the positive attitude of his teachers and their willingness to support him. The boy graduated his class successfully. He was not involved in delinquent behavior during this period. His charges are expected to be dropped in two months.

These two cases illustrate the majority of situations encountered by the program counselors, as well as interventions performed by them. The counselors' work involves mediation between the family and the JPS and other community services, as well as parental guidance. The counselors who were interviewed report positive outcomes in both cases, such as better family environment, improved academic and social functioning, and lack of recidivism on 
part of the adolescents. It should be stressed, though, that since this paper is not based on a controlled study, other factors may well contribute to these outcomes.

\section{Discussion}

Immigrant adolescents are an at-risk population with regard to anti-social behavior (Killian, 2002). Among the key contributing factors to such behavior are the relationships of these youths with their parents. Parents' emotional or physical unavailability, difficulties in balancing cultural identities, the child's unwitting transformation into the parents' cultural and linguistic mediator, among others, can compromise the parents' ability to be involved with their adolescent's life, to set clear boundaries, and to provide adequate supervision of his or her conduct. Previous studies have found that immigrant youths who have been involved in anti-social behavior have impaired relationships with their parents (Edelstein \& BarHamburger, 2007; Horowitz \& Brosh, 2011). If so, one of the main goals of professional intervention with these youths must be to support and empower their parents with the aim of improving their relationship with their adolescent children.

The Family Assistance Program counselors spend much of their time guiding and training parents in matters such as setting boundaries, developing effective communication, resolving conflicts, and understanding the youth's developmental needs, through private sessions, or group workshops and lectures. By helping parents navigate bureaucratic procedures, and by mediating between them and various public institutions, the counselors relieve the children of the burden of cultural mediation, and bolster the parents' image as independent figures capable of resolving problems on their own (Trickett \& Jones, 2007). This removes much of the stress that the parents feel while grappling with the pressures and difficulties of adapting to life in Israel (Yakhnich, 2008), and allows them to become more emotionally involved in their children's lives. The counseling work with the parents includes discussions about cultural differences between Israel and the FSU in such fields as authority and hierarchy in the family; acceptable disciplinary measures; accommodating the child's emotional needs; the educational system and parents' role in it, etc. This discourse helps to reconcile the "adaptive adult" image held by the immigrant parents with the confusing and seemingly contradictory messages they receive from the Israeli social environment and educational system (Dwairy \& Dor, 2009; Roer-Strier \& Rosenthal, 2001). In other words, the program works indirectly to change the adolescent's behavior and rehabilitate him, by improving the atmosphere at home, the adolescent's relationship with his parents, and the parents' function.

Another key aspect of the program's work is strengthening the relationship between the adolescents' families and the JPS. Due to cultural differences, language difficulties, and a high level of suspicion on the part of immigrant parents (Sakin, 2009), probation officers often find it difficult to provide an optimal solution for the children of these families, when parents prevent their children from reaching the JPS, object to psychological evaluations, or refuse to divulge what happens within the family. The Family Assistance Program helps the families to see the probation officer as a partner rather than as an adversary, thereby ensuring the youths are not withdrawn prematurely from the program. To this end, the fact that the counselors are themselves former immigrants from the FSU is a crucial advantage. Based on the interviews with both probation officers and program staff, it appears that the families trust the counselors much more than they might otherwise, since it means that they can speak in the language in which they feel most comfortable, feel included and understood, and are not subjected to ethnic stereotyping. Similarly, the probation officers see the counselors as an indispensable resource when it comes to understanding the cultural reasons behind the families' 
behavior, to questioning and examining sensitive issues, and generally as linguistic and cultural go-betweens. In the years since the program began, many close collaborative bonds have formed between program counselors and probation officers, with both sides seeing themselves as working toward a common goal of rehabilitating errant youths and returning them to a normative path, using the unique tools and resources that each party brings to the process.

Putnam (1995) proposed a concept “social capital”. This concept, referring to characteristics of social structure that encourage coordination and cooperation among people for their mutual benefit, may be useful in understanding the present program. Social capital that promotes personal growth of children and adolescents is a product of human relationships in the family, the community, and other social settings, and depends on the degree of mutual trust and commitment of its members (Coleman, 1988; Putnam, 1995). Social capital of children and adolescents is based, in part, on physical presence of their parents, their attention and involvement in their children's life (Coleman, 1988; Freistadt \& Strohschein, 2013; Putnam, 1995). If these conditions are not met for any reason, parents will not be able to transfer their personal resources (skills, values, knowledge) to their children. The child's development is also closely related to resources found outside his family, which is reflected in his parents' relationships with community settings to which the child belongs (Pitt-Catsouphes, MacDermid, Schwarz, \& Matz, 2006). The Family Assistance Program increases the social capital of immigrant youth involved in criminal behavior by tightening their relationships with their parents, encouraging parental involvement, and strengthening ties between the family and the probation service, which constitutes a significant setting for the children at this stage in their lives. This work is especially important for immigrant families, whose social capital is limited because of disconnection from distant family members, communication difficulties, and sense of alienation and social isolation.

Although, to date, there has been no evaluation study to provide objective measures of the program's effectiveness, the feedback from the field - probation officers, educators, and social workers - is encouraging. During the interviews, JPS officials have expressed great appreciation for the counselors' work and hope that its scope will be extended to cover other immigrant populations. Another indicator of the program's effectiveness is that there have been virtually no instances of families withdrawing from the counseling process; indeed, many families have asked to stay in touch with the program counselors even after the criminal charges are dropped, in hope of receiving further parental guidance, emotional support, mediation with public institutions, etc.

Since the program is still in its experimental stage, it has had to work out various complex issues, such as choosing and training suitable counselors. Much emphasis is placed during the recruitment process on the need for counselors with a strong connection with both Russian and Israeli cultures, since, as the intermediary between the family and the host society, they must represent and feel equally at home in both cultural contexts. In other words, a key criterion when gauging the suitability of a candidate for a counseling position is whether they have a bicultural identity, or as Berry puts it, whether they can serve as part of the immigrant's strategy of integration into the host society (Berry, 1997). However, that in itself is not enough: While the current three counselors all meet that first requirement, they vary greatly in their professional background - one holds a Ph.D. in educational psychology, another was trained in psychodrama, and the third is a professional mediator with a degree in sociology which means that they tend to have very different ways of working. To smooth out these differences and ensure consistency in their work as counselors, all recruits undergo professional training with the program coordinator. In addition, a staff meeting is held every week in 
which the counselors discuss professional dilemmas and formulate appropriate solutions to address the needs of the client families and the program's aims. These activities constitute significant components of program's process evaluation.

The Family Assistance Program is not the only one offered to immigrant families; there is a wide range of services designed for immigrant youth and their families. Whereas, this program focuses on immigrant juvenile delinquents, their parents, and their relationships with the Israeli criminal justice services, other programs primarily aim at normative youth not involved in criminal behavior. For example, the Immigrant Pupils Absorption Department at the Israeli Ministry of Education operates a variety of programs aimed at promoting immigrant students' integration in the education system (Israeli Ministry of Education, 2013). A non-profit "Yedidim" (meaning, Friends) organization initiates original and creative projects designed to encourage the social, educational, and employment integration of immigrant youths (Yedidim Organization, 2013). An exception is a program called "Sicuim" (Chances), which is operated by Yedidim Organization and the JPS, and aimed at reintegrating immigrant youth delinquents in a normative society. The intervention is targeted at the adolescents themselves, while the parents are informed about their children's participation in the program, but don't take part in it (Edelstein, 2010). Immigrant parents' needs are addressed by municipal social and psychological services, and sometimes by the schools. The Israeli Anti-Drug Authority organizes parents' groups for Russian-speaking parents across the country, with an emphasis on developing parenting skills and preventing risk behaviors (Israeli Anti-Drug Authority, 2008). These groups focus primarily on prevention rather than actually dealing with youths' anti-social behavior, and don't provide assistance and support outside the group activity hours. Although this list does not cover all services designed for immigrant parents and their adolescent children in Israel, it can be seen that the Family Assistance Program is a unique service providing continuous and extensive guidance for immigrant parents whose adolescent children are involved in crime. This guidance is focused on strengthening the family, mediating between the parents and the JPS and other community services, and promoting family integration and proper functioning. These ingredients fit the program exactly to the needs of its target population.

In summary, the Family Assistance Program is the result of a tripartite collaboration between the Ministry of Immigrant Absorption, the Juvenile Probation Service, and the Forum of Immigrant Parents Association. This unique program addresses the needs of immigrant families from the FSU whose children have encountered trouble with the law. These families have diverse needs involving both cultural adaptation and dealing with their children's delinquency. The program offers help tailored to the families' unique needs, with an emphasis on cultural sensitivity and mediation. In its seven years of operation to date, its counselors have helped over 600 families, gained valuable experience, developed effective working methods, and formed positive and constructive working relationships with the Juvenile Probation Service and other community services. To continue the program's development, to optimize its working methods, and to expand its scope to other geographical areas and sectors of the population, an in-depth evaluation study is needed to examine various aspects of the program's operation and pave the way to developing it further and mapping out its work in the long term. 


\section{Implications for Practice}

The pilot program presented in this paper may provide valuable knowledge and serve as an inspiration to social workers, educators, and other professionals involved in helping immigrant adolescents and their families. Although the program operates in the Israeli social context and is aimed at FSU immigrants, its experience may be widely applicable to other immigration-receiving countries, and with various immigrant populations. Its main assertion that an immigrant delinquent adolescent's rehabilitation may be achieved through strengthening his family - is compatible with social services professional ideology, as well as with most immigrant populations' cultural backgrounds (with the majority of immigrants in Western countries coming from collectivist societies). In terms of policy, immigrant-receiving states may consider making such a program an integral link in the chain of treating immigrant delinquent youth, with each family being automatically referred to a program counselor. The counselor's role as language and cultural mediator, his in-depth familiarity with immigrant families' realities as well as with police, court and probation service functions, coupled with his professional skills, can bridge the gap between the family and the officials, empower the parents and promote the youth rehabilitation process. In terms of practice, it would be helpful to train professional counselors to work with specific immigrant groups, so the counselor and the family share their cultural background and heritage. Aside from cultural background, counselors' personality, their perception of optimal integration, cultural tolerance and sensitivity, as well as their professional background, should be taken into account during recruitment and training. Ultimately, program implementation should be thoroughly evaluated in order to promote its efficiency and suitability to immigrant families' needs. 


\section{References}

Bankston III, C. L. (1998). Youth gangs and the new second generation: A review essay. Aggression and Violent Behavior, 3(1), 35-45. http://dx.doi.org/10.1016/s1359-1789(97)00010-4

Berry, J. W. (1997). Immigration, acculturation, and adaptation. Applied Psychology: An International Review, 46(1), 5-34. http://dx.doi.org/10.1111/j.1464-0597.1997.tb01087.x

Bronshtein, A., \& Bar-On, N. (2008). Evaluation of immigrant parent groups for the Israeli Anti-Drug Authority. Jerusalem: National Anti-Drug Authority of Israel.

Coleman, J. S. (1988). Social capital in the creation of human capital. The American Journal of Sociology, 94(Suppl.), 95-120.

Cosher, H., Ben-Arie, A., \& Cohen, S. (2011). Immigrant children in Israel 2011. Jerusalem: The Israel National Council for the Child.

Dwairy, M., \& Dor, A. (2009). Parenting and psychological adjustment of adolescent immigrants in Israel. Journal of Family Psychology, 23(3), 416-425. http://dx.doi.org/10.1037/a0015830

Edelstein, A. (2010). Factors reducing risk behaviors: An evaluation of "Sicuim” program. MeNituk LeShiluv, 16, 75-98.

Edelstein, A., \& Bar-Hamburger, R. (2007). Substance use and related delinquency among former Russian youth in Israel. Jerusalem: National Anti-Drug Authority of Israel.

Forum of Immigrant Parents. (2014). Retrieved July 10, 2014, from http://www.pforum.org.il/ heb/Default.aspx?g=project\&id=43.

Freistadt, J., \& Strohschein, L. (2013). Family structure differences in family functioning: Interactive effects of social capital and family structure. Journal of Family Issues, 34(7), 952-974. http://dx.doi.org/10.1177/0192513x12447054

Granic, I., \& Patterson, G. R. (2006). Toward a comprehensive model of antisocial development: A dynamic systems approach. Psychological Review, 113(1), 101-131. http://dx.doi.org/10.1037/0033-295x.113.1.101

Henry, H. M., Stiles, W. B., \& Biran, M. W. (2005). Loss and mourning in immigration: Using the assimilation model to assess continuing bonds with native culture. Counseling Psychology Quarterly, 18(2), 109-119. http://dx.doi.org/10.1080/09515070500136819

Henry, H., Stiles, W. B., Biran, M. W., \& Hinkle, S. (2008). Perceived parental acculturation behaviors and control as predictors of subjective well-being in Arab American college students. The Family Journal, 16, 28-34. http://dx.doi.org/10.1177/1066480707309126

Hirschi, T. (1969). Causes of delinquency. Berkeley: University of California Press.

Hoersting, R. C., \& Jenkins, S. R. (2011). No place to call home: Cultural homelessness, selfesteem and cross-cultural identities. International Journal of Intercultural Relations, 35(1), 17-30. http://dx.doi.org/10.1016/j.ijintrel.2010.11.005 
Horowitz, T., \& Brosh, T. (2011). Patterns of drug and alcohol abuse among youth from the former Soviet Union. Jerusalem: The Henrietta Szold Institute.

Israeli Anti-Drug Authority. (2008). Evaluation of immigrant parent groups for the Israeli Anti-Drug Authority. Jerusalem: Author.

Israeli Ministry of Education. (2013). Immigrant Pupils Absorption Department. Retrieved October, 2013 from http://cms.education.gov.il/EducationCMS/Units/olim.

Janssen, M. M., Verhulst, F. C., Bengi-Arslan, L., Erol, N., Salter, C. J., Crijnen, A. A. M. (2004). Comparison of self-reported emotional and behavioral problems in Turkish immigrant, Dutch and Turkish adolescents. Social Psychiatry and Psychiatric Epidemiology, 39(2), 133-140. http://dx.doi.org/10.1007/s00127-004-0712-1

Jones, C., Trickett, E., \& Birman, D. (2012), Determinants and consequences of child culture brokering in families from the former Soviet Union. American Journal of Community Psychology, 50(1/2), 182-196. http://dx.doi.org/10.1007/s10464-012-9488-8

Killian, C. (2002). Bicultural competence: A means of crime reduction among the children of immigrants? In J. D. Freilich, G. Newman, S. G. Shoham, \& M. Addad (Eds.), Migration, culture conflict and crime (pp. 121-130). Burlington, VT: Ashgate Publishing Company.

Leipzig, C. (2006). When Russians come to therapy. The American Journal of Family Therapy, 34(3), 219-242. http://dx.doi.org/10.1080/01926180600550379

Mann, M. A. (2004). Immigrant parents and their emigrant adolescents: The tension of inner and outer worlds. The American Journal of Psychoanalysis, 64(2), 143-153. http://dx.doi.org/10.1023/b:tajp.0000027269.37516.16

Ministry of Social Affairs and Social Services. (2013). Probation Services Department. Retrieved February 3, 2013, from http://www.molsa.gov.il/UNITS/WINGS/AGAFNOAR/SHERUTMIVHANLANOAR /Pages/SherutMivhanLanoar.aspx.

Mirsky, J. (1997). Psychological distress among immigrant adolescents: Culture-specific factors in the case of immigrants from the former Soviet Union. International Journal of Psychology, 32(4), 221-230.

Mirsky, J. (2012). Social deviance among immigrant adolescents from the former Soviet Union in Israel: Data and risk factors. Anales de Psicología, 28(3), 675-682.

Mirsky, J., \& Peretz, Y. (2006). Maturational opportunities in migration: Separationindividuation perspective. International Journal of Applied Psychoanalytic Studies, 3(1), 51-64. http://dx.doi.org/10.1002/aps.48

Oznobishin, O., \& Kurman, J. (2009). Parent-child role reversal and psychological adjustment among immigrant youth in Israel. Journal of Family Psychology, 23(3), 405415. http://dx.doi.org/10.1037/a0015811 
Phinney, J. S., Horenczyk, G., Liebkind, K., \& Vedder, P. (2001). Ethnic identity, immigration, and well-being: An interactional perspective. Journal of Social Issues, 57(3), 493-510. http://dx.doi.org/10.1111/0022-4537.00225

Pitt-Catsouphes, M., MacDermid, S. M., Schwarz, R., \& Matz. C. (2006). Community contexts: The perspectives and adaptations of working parents. American Behavioral Scientist, 49(10), 1400-1421. http://dx.doi.org/10.1177/0002764206286562

Pollock, D., \& Van Reken, R. (1999). Third culture kids: The experience of growing up among worlds. Yarmouth, ME: Intercultural Press.

Portes, A., Fernandez-Kelly, P., \& Haller, W. (2009). The adaptation of the immigrant second generation in America: Theoretical overview and recent evidence. Journal of Ethnic and Migration Studies, 35(7), 1077-1104. http://dx.doi.org/10.1080/13691830903006127

Portes, A., \& Rumbaut, R. G. (2001). Legacies: The story of the immigrant second generation. Berkeley, CA: University of California Press and Russell Sage Foundation.

Putnam, R. (1995). Bowling alone: America's declining social capital. Journal of Democracy, 6(1), 65-78. http://dx.doi.org/10.1353/jod.1995.0002

Roer-Strier, D., \& Rosenthal, M. K. (2001). Socialization in changing cultural contexts: A search for images of the “adaptive adult”. Social Work, 46(3), 215-228. http://dx.doi.org/10.1093/sw/46.3.215

Sakin, A. (2009). The willingness of immigrants from the former Soviet Union to participate in psychosocial substance abuse treatment. Unpublished master's thesis, University of Haifa, Haifa, Israel.

Sam, D. L., Vedder, P., Liebkind, K., Neto, F., \& Virta, E. (2008). Immigration, acculturation and the paradox of adaptation in Europe. European Journal of Developmental Psychology, 5(2), 138-158. http://dx.doi.org/10.1080/17405620701563348

Slonim-Nevo, V., Sharaga, Y, \& Mirsky, J. (1999). A culturally sensitive approach to therapy with immigrant families: The case of Jewish emigrants from the former Soviet Union. Family Process, 38(4), 445-461. http://dx.doi.org/10.1111/j.1545-5300.1999.00445.x

Strier, R., \& Roer-Strier, D. (2005). Fatherhood and immigration: Perceptions of Israeli immigrant fathers from Ethiopia and the former Soviet Union. Families in Society, 86(1), 121-133. http://dx.doi.org/10.1606/1044-3894.1884

Tartakovsky, E., \& Mirsky, J. (2001). Bullying gangs among immigrant adolescents from the former Soviet Union in Israel. Journal of Interpersonal Violence, 16(3), 247-265. http://dx.doi.org/10.1177/088626001016003005

Titzmann, P. F., Raabe, T., \& Silbereisen, R. K. (2008). Risk and protective factors for delinquency among male adolescent immigrants at different stages of the acculturation process. International Journal of Psychology, 43(1), 19-31. http://dx.doi.org/10.1080/00207590701804305

Trickett, E. J., \& Jones, C. J. (2007). Adolescent culture brokering and family functioning: A study of families from Vietnam. Cultural Diversity and Ethnic Minority Psychology, 13(2), 143-150. http://dx.doi.org/10.1037/1099-9809.13.2.143 
Tsang, A. K. T., Irving, H., Alaggia, R., Chau, S. B. Y., \& Benjamin, M. (2003). Negotiating ethnic identity in Canada: The case of the "satellite children". Youth and Society, 34(3), 359-384. http://dx.doi.org/10.1177/0044118x02250124

van Leeuwen, N., Rodgers, R. F., Bui, E., Pirlot, G., \& Chabrol, H. (2014). Relations between acculturation orientations and antisocial behavior in adolescents and young adults from immigrant families. International Journal of Culture and Mental Health, 7(1), 68-82. http://dx.doi.org/10.1080/17542863.2012.699534

Vivero, V. N., \& Jenkins, S. R. (1999). Existential hazards of the multicultural individual: Defining and understanding “cultural homelessness”. Cultural Diversity and Ethnic Minority Psychology, 5, 6-26. http://dx.doi.org/10.1037/1099-9809.5.1.6

Walsh, S. D., \& Tartakovsky, E. (2011). The relationship between different components of national identities and psychosocial adjustment among high-school adolescent immigrants from Russia and Ukraine in Israel. European Journal of Developmental Psychology, 8(4), 452-472. http://dx.doi.org/10.1080/17405629.2010.549014

Ward C. L., \& Laughlin, J. E. (2003). Social contexts, age, and juvenile delinquency: A community perspective. Journal of Child and Adolescents Mental Health, 15, 13-26. http://dx.doi.org/10.2989/17280580309486536

Yakhnich, L. (2008). Immigration as a multiple-stressor situation: Stress and coping among immigrants from the former Soviet Union in Israel. International Journal of Stress Management, 15(3), 252-268. http://dx.doi.org/10.1037/a0013002

Yakhnich, L. (2010). Immigrant adolescents from the former Soviet Union in Israel - risk and adaptation. Hed HaUlpan HaHadash, 97, 64-70.

Yakhnich, L. (in press). Group work with Russian immigrant parents: Preventing risk behavior among second generation youth. In E. Grupper and S. Romi (Eds.), Promoting children and adolescents at risk in Israel: The field's structure of knowledge, intervention methods, training programs and future development.

Yedidim Organization. (2013). Retrieved September 30, 2013 from http://www.yedidim.org.il/node/43. 